\title{
Initial Hunger Meal Pattern and 20\% Reduction in Energy Intake
}

\author{
Mario Ciampolini \\ Preventive Gastroenterology Unit, Department of Paediatrics, Università di Firenze, Florence, Italy \\ Email: mlciampolini@fastwebnet.it
}

How to cite this paper: Ciampolini, M. (2017) Initial Hunger Meal Pattern and $20 \%$ Reduction in Energy Intake. Open Journal of Preventive Medicine, 7, 195-201. https://doi.org/10.4236/ojpm.2017.710015

Received: September 26, 2017

Accepted: October 20, 2017

Published: October 23, 2017

Copyright $\odot 2017$ by author and Scientific Research Publishing Inc. This work is licensed under the Creative Commons Attribution International License (CC BY 4.0).

http://creativecommons.org/licenses/by/4.0/ (c) (i) Open Access

\begin{abstract}
At meals, people aim to maintain their usual energy level and balance in blood and all tissues. People have subjectively refined this aim through poorly conscious months and years, i.e., outside any comparison with other people, other times or feeding conditions. The preprandial weekly mean blood glucose can assess this individual aim that differs from other people in the general fattening/ diabetes development. The evaluation of this pathogenic development in the overall stratification shows how unhealthy is the subject's energy imbalance. After 2 - 48 hours of meal suspension, the aim arises as Initial Hunger. This Initial Hunger serves as reference sensation in the assessment of current energy availability. Recognition of three Initial Hunger arousals per day produces an even energy balance and eliminates any conditioned intake. This meal pattern seemed a useful chance to reverse current trends in overweight increase. Two reliable authorities (National Institute of Health and New England Journal of Medicine) noticed that already, all dieticians instructed to wait for hunger arousal before meals to limit energy intake for body weight loss. Dieticians' definition and instructions on hunger for body weight loss miss any distinction from conditioned energy intake and are ineffective. Present report shows the need for improving awareness on hunger.
\end{abstract}

\section{Keywords}

Blood Glucose, Diabetes, Insulin Resistance, Overweight, Fattening, Energy Balance, Energy Intake, Limit in Energy Intake, Hunger, Meal Onset, Energy Availability, Bowel Disorders, Malnutrition

\section{Introduction}

At meals, people aim to maintain their usual energy level and balance in blood and all tissues (Figure 1, Figure 2) [1]. People have subjectively refined this aim 


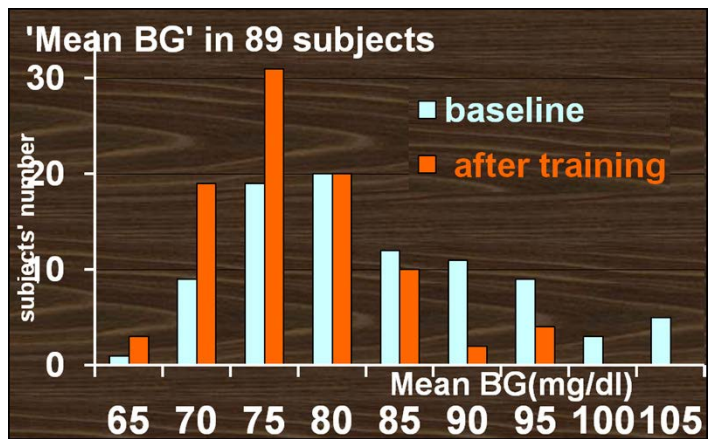

Notes: Strata consist of subjects with no significant difference in mean BG inside the stratum. Moreover, each stratum excludes subsequent subjects whose mean BG is significantly higher than that of the first subject in the stratum. Column height shows the first component. Mean BG is reported in sequentially increasing order at recruitment, not in linear correlation with segment length on the x-axis scale. Abbreviation: BG: Blood Glucose. Mean BG: Mean of 21 preprandial measurements by portable device reported by home week diary. Copyright: @ 2016 Ciampolini et al.

Figure 1. Increasing sequence of Mean BGs of all 89 trained subjects divided into ten strata (columns) at recruitment and into 8 strata 5 months after training.

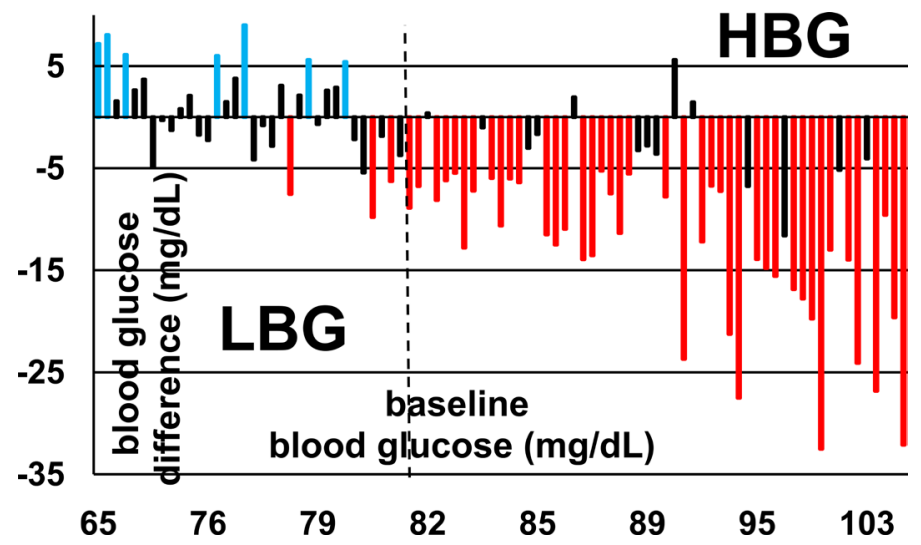

Notes: Column height shows 5 months after pretraining mean BG difference in each trained subject. Significant increases are indicated by blue bars, significant decreases by red bars, and not significant changes by black bars. Mean BG is reported in sequentially increasing order at recruitment, not in linear correlation with segment length on the $\mathrm{X}$-axis scale. The range of mean blood glucose values at recruitment is indicated by the minimum and maximum values for the first and last subjects (large arrows). The vertical dashed line indicates the most significant division between subjects who showed no mean BG decrease after training (low BG group, $\mathrm{n}=34$ ) and those who showed significant decrease of mean BG (high BG group, $n=55$; Chi-squared analysis: $P=0.00001$ ). This threshold blood glucose at recruitment (demarcation point) is $81.8 \mathrm{mg} / \mathrm{dL}(4.5 \mathrm{mmol} / \mathrm{L})$ at recruitment in the randomized controlled studies. Subjects above this threshold accounted for most of the improvements in weigh and insulin resistance. (Image courtesy of Ciampolini et al., reference 2). Copyright $($ 2) 2011, Dove Medical Press Ltd.

Figure 2. Difference of mean preprandial BG after training versus BG at recruitment for each trained subject.

through poorly conscious months and years, i.e., outside any comparison with other people, other times or feeding conditions. The preprandial weekly mean blood glucose (MBG, obtained by self-reported diaries) can assess this individual aim that differs from other people in the general fattening/diabetes development [2] [3]. This pathogenic development is stratified in the overall population and MBG also assesses how unhealthy is the subject's energy imbalance. After 2 - 48 
hours of meal suspension, the aim arises as Initial Hunger (IH [1]). This IH serves as reference sensation in the assessment of current energy availability. Recognition of three IH arousals per day produces an even energy balance and eliminates any conditioned intake [1] [2] [3]. This meal pattern seemed a useful chance to reverse current trends in overweight increase. Two reliable authorities (National Institute of Health and New England Journal of Medicine; NIH, NEJM) noticed that already, all dieticians instructed to wait for hunger arousal before meals to limit energy intake for body weight loss. The word hunger in the dieticians', in NIH and in NEJM context is deceiving; it refers to the conditioned type of hunger. The word hunger also evokes a different subjective state: hunger due to meal suspension. The distinction between this hunger from conditioned hunger requires long focusing on subsequent meal onsets for about a week [1] [2] [3]. Conditioned hunger as a sensation consists of the same gastro-duodenal peristaltic movements that characterize hunger after meal suspension (IH) and occasionally, may be more intense. The main difference resides in the onset: either before or after noticing meal cues (e.g., ready table before meal). Did mothers and dieticians focus on meal onset when reporting no food offering? What did dieticians ascertain about the signal of demand by the child or the adult? Did dieticians assess food demand in absence of any food cue? Did the child's demand consist in walking, crying, indicating, mood change or searching for food? After usual scheduled time, how long did mothers (and adults for themselves) wait before responding to a food demand from their child? Did mothers try to distract child from food? How long before meals did the adult subject perceive the hunger sensation? Did adult subjects report gastric sensations or physical weakness before the meal? Did mothers and adult subjects use a portable device to measure BG? Did they become able to predict measurement values? Mean absolute error (difference between BG measurement by portable device and autoanalyzer) was $5.7 \mathrm{mg} / \mathrm{dL}$ in 85 blood sample comparisons [1] [2] [3]. This mean error was an overestimation (too high) because the mean included two overtly erroneous differences (out layers). Although high, $5.7 \mathrm{mg} / \mathrm{dL}$ is an error that allows definite conclusions. Low BG was $76.6 \pm 3.7 \mathrm{mg} / \mathrm{dL}$ at the moment of IH perception. This value sharply distinguished IH from conditioned intake.

The proposed Initial Hunger Meal Pattern (IHMP) was not constructed to reach a $B G$ of $76.6 \pm 3.7 \mathrm{mg} / \mathrm{dL}$, i.e. IHMP did not rely on BG measurements. Patients had not to measure BG before all meals. They decided meal onset on hunger sensation arousal they had learned to recognize. This sensation was initially validated by BG measurement after meal suspension. Afterwards, subjects relied on the learned $\mathrm{IH}$ recognition to decide meal onset. BG measurements were sometimes useful in checking subjective mothers' IH and BG estimation. The same BG measurement after many years showed that IH corresponded to an identical biochemical condition. Adjusting energy administration to the planned IH arousals was successful most of the times [2] [3] [4]. E.g., mothers gave a large milk amount and delayed meal demand by their child. Any added energy rich administration proportionately delayed IH arousal. Using this rule and re- 
lying on accurate estimation of current BG and $\mathrm{IH}$ recognition, trained adults obtained a coincidence about hunger arousal and the planned meal onset more than $90 \%$ of times. This meal pattern had the name of Initial Hunger Meal Pattern.

\section{Words with Experienced Meaning versus Words with on the Surface Meaning}

Control subjects answered to the question "are you hungry?" before breakfast and most of them answered: I am hungry of course, I had not yet breakfast, I am always hungry before the meal [1]. If I am not hungry, I do not eat. Controls' hunger was different (conditioned) from hunger of trained people. NIH and NEJM, dieticians and untrained patients reported the word "hunger" with the same meaning that control subjects reported in the lab before breakfast [1]. In studies on $\mathrm{IH}$, trained patients elaborated the hunger sensation through multiple arousals in a week. BG measurements confirmed the different biochemical backgrounds between trained and control subjects [1]. More than two thirds of control untrained subjects were unable at recognizing current BG and IH.

\section{Results and Discussion}

Adults had to learn recognition of IH sensations and let coincide future arousals of IH sensation with the planned mealtimes. Members of SSIB already questioned how such coincidences were possible. Homo sapiens are capable to recognize many more sensations than the well-known sensations obtained by 6 senses: sounds, rhythms, figures, abdominal pain, headache... Accurate estimation of current BG after training demonstrated that humans learn sensations of current energy availability. These recognition activities remained useless and neglected for long time. Unexplored sensations do not mean that hunger sensations do not exist or have to remain outside the realm of science, much more that the IH recognition curbed conditioned intake by an individual amount that was related to the energy intake and $B G$ at recruitment. The trained meal pattern significantly and largely decreased mean energy intake, Preprandial Mean BG, Resting Metabolic Rate by indirect calorimetry, Total Energy Expenditure by doubly labelled water and insulin resistance by glucose tolerance texts for about $15 \%-30 \%$ together with body weight decrease [1]-[6]. Body weight did not decrease in those who were both normal weight and insulin sensitive. These results correspond to prevention of fattening, diabetes and associated vascular and malignant diseases [7].

Unfortunately, a good nutrition requires also physical activity and dilution of energy by NSV to stop energy intake [8]. A three factors use is an error in a scientific comparison study. The three factors association might be more effective on health than the sum of their separate effects. We preferred to be of help for mothers and for children who asked advice than improving the success chances of the research. The increase in not starchy vegetables (NSV) intake 
partly contributed to lower energy intake and body weight decrease. Further body weight decrease was possible only after the MBG decrease [5] that is associated with recognition of Initial Hunger (IH). The conditioned intake suppression was actual and effective.

The attraction power of conditioned intake may be overestimated. The attraction power of conditioned meals is often weaker than the hunger that emerges after eating suspension. Conditioned meal attraction easily fades for change in attention objective. The conditioned attraction may be sufficient for eating in association with insulin resistance for long time and large part of population. Two overweight diabetic people maintained low intake (200 to $400 \mathrm{kcal}$ per day) for 4 - 12 months. Difficulties emerged in the confrontation with population. People asked if the overweight/diabetic subject was celiac because he did not eat bread and pasta. Living seems to consist in consuming energy rich food for most people. Children require an education to control (contrast) the preference for energy rich food. Intake of essential principles is small when meal energy density is high [6]. All population has to increase familiarity with energy content of food, energy expenditure in different environments and has to improve estimation of current energy availability. Intake of only 100 grams of meat and 200 300 grams vegetables was even sometimes sufficient for a child meal, although the energy content is poor. Relatives easily blamed mothers by noticing prevalent NSV intake by child. Yet every energy intake over an even balance has an immune price, a damage that may be small as well as large.

\section{Conclusion}

Conditioned eating involves hunger in a tremendous ambiguity. Suspension of meals for no more than two days allows Initial Hunger arousal in a negative relation to age. Dieticians and Nutritionists have to refer to this personal experience when they speak of Initial Hunger.

\section{Acknowledgements}

The Author acknowledges the indispensable collaboration in writing with David Lowel-Smith (NZ) and Riccardo Bianchi (NY), and the strategic, statistical support by Cutberto Garza (Rector, Boston College), Giuliano Parrini (Professor of Physics, Firenze) and Andrea Giommi (Professor of Statistics, Firenze).

The here summarized researches were supported by the Italian Ministry of University, Research, Science and Technology grants for the years 1998-2002 and by ONLUS Nutrizione e Prevenzione, Firenze, for the years 2003-2012. This review has been shown in: "Modifying Eating Behavior: Novel Approaches for Reducing Body Weight, Preventing Weight Regain and Reducing Chronic Disease Risk” ASN's Annual Meeting \& Scientific Sessions at Experimental Biology 2014, April 26-30.

\section{Conflict of Interests}

No conflicts of interest. 


\section{References}

[1] Ciampolini, M. and Bianchi, R. (2006) Training to Estimate Blood Glucose and to form Associations with Initial Hunger. Nutrition \& Metabolism, 3, 42.

http://www.nutritionandmetabolism.com/content/3/1/42 https://doi.org/10.1186/1743-7075-3-42

[2] Ciampolini, M. and Sifone, M. (2011) Differences in Maintenance of Mean Blood Glucose (BG) and Their Association with Response to "Recognizing Hunger". International Journal of General Medicine, 4, 403-412.

http://www.dovepress.com/articles.php?article $\mathrm{id}=7556 \& \mathrm{l}=\mathrm{BLE} 3 \mathrm{wJ}$ 5mAFXtoDH ARiR88kX112820 https://doi.org/10.2147/IJGM.S19035

[3] Ciampolini, M. (2012) Requested Meals versus Scheduled Meals. International Journal of General Medicine, 5, 1-9.

http://www.dovepress.com/article 9690.t9911652 https://doi.org/10.2147/IJGM.S29889

[4] Ciampolini, M., Brenna, J.T., Giannellini, V. and Bini, S. (2013) Interruption of Scheduled, Automatic Feeding and Reduction of Excess Energy Intake in Toddlers. International Journal of General Medicine, 6, 39-47. https://doi.org/10.2147/IJGM.S39946

[5] Ciampolini, M., Lovell-Smith, D. and Sifone, M. (2010) Sustained Self-Regulation of Energy Intake. Loss of Weight in Overweight Subjects. Maintenance of Weight in Normal-Weight Subjects. Nutrition \& Metabolism, 7, 14.

http://www.ncbi.nlm.nih.gov/pubmed/23393411 https://doi.org/10.1186/1743-7075-7-4

[6] Ciampolini, M. (2017) Positive Energy Imbalance and Microflora Overgrowth. International Journal of Pediatrics \& Neonatal Care, 7, Article ID: 00282.

[7] Gregg, E.W. and Shaw, J.E. (2017) Global Health Effects of Overweight and Obesity. The New England Journal of Medicine, 377, 80-81.

https://doi.org/10.1056/NEJMe1706095

[8] Ciampolini, M. (2016) Residue, Fiber, and Subjectivity. Advances in Nutrition, 7, 420. https://doi.org/10.3945/an.115.010074 


\section{List of Abbreviations and Terms}

BG = Blood Glucose, an index of energy availability in blood for the whole body

$\mathrm{RMR}=$ resting metabolic rate

TEE $=$ daily total energy expenditure

$\mathrm{OW}=$ overweight, $\mathrm{BMI}>25 ; \mathrm{NW}=$ Normal body weight, $\mathrm{BMI}$ under 25 .

$\mathrm{BMI}=$ body mass index $=$ body weight in $\mathrm{kg}$ divided by squared height in meters

IHMP: Initial Hunger Meal Pattern: Energy intake is adjusted to three arousals of IH per day.

$\mathrm{IH}=$ Initial Hunger consists of gastric pangs or mind or physical weakness. In sedentary adults and in children, IH corresponds to low BG: $76.6 \pm 3.7 \mathrm{mg} / \mathrm{dL}$.

High BG is over $81.8 \mathrm{mg} / \mathrm{dL}$ and Low BG is a BG below $81.8 \mathrm{mg} / \mathrm{dL}$, respectively associated with insulin resistance and insulin sensitivity.

$\mathrm{MBG}=$ The mean of $21 \mathrm{BG}$ measurements before the three main daily meals reported by a weeklydiary. MBG reproducibly measures the compliance with IHMP, the changes after training and is negatively correlated to insulin sensitivity. Below $81.8 \mathrm{mg} / \mathrm{dL}$ (Low BG) MBG indicates a healthy meal pattern in sedentary people. Over $81.8 \mathrm{mg} / \mathrm{dL} \mathrm{MBG}$ is associated with fattening/insulin resistance.

NSV = Non-starchy Vegetables, food with lower content than $30 \mathrm{kcal} / 100 \mathrm{grams}$

SSIB $=$ Society for the Study of Ingestive Behavior

$\mathrm{NIH}=$ National Institute of health 